\title{
Personality Differences between Male Indian Classical Dancers and Male Western Dancers
}

\author{
Preeti Joshi, Prashant Das
}

\begin{abstract}
The present research was conducted to study personality differences between male Indian Classical dancers and male western dancers. The need to carry out this research was because not many researches in this area including these variables and groups have been conducted before in an Indian context. The sample size of this research was 10 adult males (5 Indian classical dancers and 5 western dancers). NEO-FFI scale was used to assess the different dimensions of the personality of the participants. Results revealed that there is a significant difference in the dimension of openness.
\end{abstract}

Keywords: Personality, Indian classical and Western Dance

\section{Introduction}

\section{Dance}

India has thousands of year old tradition of fine arts and classical and folk music and dances. Some of the worldfamous dance forms that originated and grown in India are Bharatnatyam, Kathak, Kathakali, Kuchipudi, Manipuri, Mohiniattam and Odissi. All these dance forms use basically the same 'mudras' or signs of hand as a common language of expression and were originally performed in the temples to entertain various Gods and Goddesses. They were also effective in carrying forward the various mythological stories from generation to generation while entertaining the audiences. . The Indian Classical Dance is often regarded as the form of worship and meditation. It eventually became a part of 'NatyaShashtra'. (Cultural India, n.d.).

It is through the movement of body's different parts and expressing your emotions through it is called dance.The Indian classical dance forms are those forms of dancing in which each movement from head to toe is bound by rules. Indian classical dance has a distinct character that reflects the great cultural and traditional endeavour. The forms of Indian dance have transcended beyond the fences and sociocultural hindrances. Exponents of the Indian classical dance believe that it has the calibre of creating a new and disciplined lifestyle (Indian classical dance, n.d.)

Western dance is characterised by great diversity and rapid change, many of its forms came into existence to show a sense of revolt and aggression. Most dancers of the East repeated highly refined forms of movement that had remained virtually unchanged for centuries or millennia, Western dancers showed a constant readiness, even eagerness, to accept new vehicles for their dancing. From the earliest records, it appears that Western dance has always embraced an enormous variety of communal or ritual dances, of social dance enjoyed by many different levels of society, and of skilled theatrical dances that followed distinct but often overlapping lines of development. The western dance styles are: Hip-Hop, Break Dance and Tap Dance.(Western dance, n.d.)

\section{Indian perspective on personality}

In Indian psychological thought the term 'personality' has not been used in strict sense, Swabhaava instead the concept of Swabhaava referred in scriptures, covers all aspects of personality. is the essential quality. The concept of Triguna has been utilized to explain the concept of personality in modern era as well. The development of consciousness is apparently rooted in this concept of Triguna. These are known as (sattva) called as stability; rajas called as activation and tamas called as inertia. Manas has been ascribed the functions which are mental functions and mental processes (Mnaovrittimanopravrtti).

1) Sattvaguna is the "spiritual quality". When sattvaguna is dominant, a person has inherent desire to be good and caring. There is a resolute constancy of mind and senses. When sattva is prevalent, the light of wisdom shines through the individual. Sattvic intellect clearly understands the difference between desirable and undesirable, undutiful and dutiful action. When sattva is dominant a person does his work as a duty.

2) Rajas guna is the "active quality". Rajas guna is considered to give rise to passion and desire, it causes greed, activity, undertaking of works, restlessness, and desire. Rajas dominant person is full of attachment, full of longings for fruits of action. Due to dominance of selfinterest, the intellect gives distorted picture of right and wrong

3) Tamasguna is the "material quality". Tamas arises from hopes and illusions. Tamas produces ambiguity, idleness, fantasy, and persistence. Characteristics of Tamasguna dominant people are cautious, apprehensive, and revengeful. Tamasicguna also suggests disillusionment and cynicism. When Tamasicguna is dominant, a person derives happiness which originates and ends in selfdelusion and miscomprehension. (Srivastava, K., 2012)

\section{Big 5 Personality Factors}

McCrae and his colleagues found that the big five traits are also remarkably universal. One study that looked at people from more than 50 different cultures found that the five dimensions could be accurately used to describe personality. An evolutionary explanation for these five core personality traits suggests that these personality traits represent the most important qualities that shape our social landscape.

1) Extraversion: Extraversion is characterized by excitability, sociability, talkativeness, assertiveness and high amounts of emotional expressiveness. People who are high in extroversion are outgoing and tend to gain energy in social situations. People who are low in 


\section{International Journal of Science and Research (IJSR) \\ ISSN (Online): 2319-7064}

Index Copernicus Value (2016): 79.57 | Impact Factor (2015): 6.391

extroversion (or introverted) tend to be more reserved and have to expend energy in social settings.

2) Agreeableness: This personality dimension includes attributes such as trust, altruism, kindness, affection and other prosocial behaviors. People who are high in agreeableness tend to be more cooperative while those low in this trait tend to be more competitive and even manipulative.

3) Conscientiousness: Standard features of this dimension include high levels of thoughtfulness, with good impulse control and goal-directed behaviors. Those high on conscientiousness tend to be organized and mindful of details.

4) Neuroticism: Neuroticism is a trait characterized by sadness, moodiness, and emotional instability. Individuals who are high in this trait tend to experience mood swings, anxiety, moodiness, irritability and sadness. Those low in this trait tend to be more stable and emotionally resilient.

5) Openness: This trait features characteristics such as imagination and insight, and those high in this trait also tend to have a broad range of interests. People who are high in this trait tend to be more adventurous and creative. People low in this trait are often much more traditional and may struggle with abstract thinking.

It is important to note that each of the five personality factors represents a range between two extremes. For example, extraversion represents a continuum between extreme extraversion and extreme introversion. In the real world, most people lie somewhere in between the two polar ends of each dimension.(Baron, 2013)

\section{Review of Literature}

A study on gender differences between personality traits across culture on college-age and adult samples were done in which women reported themselves to be higher in Neuroticism, Agreeableness, Warmth, and Openness to Feelings, whereas men were higher in Assertiveness and Openness to Ideas.(Yana et al., 2011)

A study on meta-analysis of personality in scientific and artistic creativity was done, in general, creative people are more open to new experiences, less conventional and less conscientious, more self-confident, self-accepting, driven, ambitious, dominant, hostile, and impulsive.(Feist et al., 1998)

Leisure activities, interests and personality traits of young dancers, spending about $15 \mathrm{~h}$ weekly on classical and modern ballet education, were assessed by means of a number of questionnaires. Results differed only slightly from those of non-dancers, although some significant differences emerged. With respect to physical self-concept and self-esteem, findings indicated significantly less favourable attitudes and less self-esteem among dancers as compared to non-dancers. (Personality and Dance, n.d.)

A research on gender differences in personality across 10 aspects of the big five personality factors was performed in which women reported higher Big Five Extraversion, Agreeableness, and Neuroticism scores than men. However, more extensive gender differences were found at the level of the aspects, with significant gender differences appearing in both aspects of every Big Five trait. (Yana et al., 2011)

Researchers at the University of Jyvaskyla in Finland gave volunteers personality tests, then observed how they broke it down to different types of music. Then they analysed their moves using motion-capture technology. They found:Extroverts move around the most, with big head and arm movements, Neurotic people do the "shuffle," jerking their hands and feet, Agreeable people are "smoother" dancers who move side to side, Open-minded people bob up and down, Conscientious people move about the dance floor the most.(What your dance moves say about your personality, n.d.)

The way you dance can reveal information about your personality. Scientists have found strong correlations between certain dancing styles and each of the personalities. Using motion capture technology, the researchers recorded the dance styles of all the volunteers as they were played each musical clip before analysing the movements using computer software.(Dance moves can reveal your personality, n.d.)

A study explored the influence of personality and trait empathy on dancers' responsiveness to small tempo differences between otherwise musically identical stimuli, measured by difference in the amount in acceleration of key joints. Thirty participants were recorded using motion capture while dancing to excerpts from six popular songs that were time-stretched to be slightly faster or slower than their original tempi. Analysis revealed that higher conscientiousness and lower extraversion both correlated with greater responsiveness to tempo change. Partial correlation analysis revealed that conscientiousness remained significantly correlated with responsiveness when extraversion was controlled, but not vice versa.(Carlson et al., 2016)

\section{Rationale of the research}

Personality of dancers and especially of male Indian classical dancers have always been subjected to questioning. The present research is conducted because the variables in this research have not been studied before with reference to the Indian classical dance and its comparison with western dance context Thus the research explores the effect of Indian classical dance on an individual's personality and also seeks to find out whether there is a difference in the personality of males involved in two different dance forms.

\section{Method}

\section{Objective}

To investigate whether there is a difference in the big five personality factors of male Indian classical dancers and male western dancers.

\section{Hypothesis}

There is no significant difference between the personality of male Indian classical dancers and male western dancers.

\section{Volume 6 Issue 12, December 2017}




\section{International Journal of Science and Research (IJSR) \\ ISSN (Online): 2319-7064}

Index Copernicus Value (2016): 79.57 | Impact Factor (2015): 6.391

\section{Variable}

For finding out the personality differences NEO-FFI was used consisted of five different dimensions:

1) Extraversion: Extraversion is characterized by excitability, sociability, talkativeness, assertiveness and high amounts of emotional expressiveness.

2) Agreeableness: This personality dimension includes attributes such as trust, altruism, kindness, affection and other pro-social behaviors.

3) Conscientiousness: Standard features of this dimension include high levels of thoughtfulness, with good impulse control and goal-directed behaviors.

4) Neuroticism: Neuroticism is a trait characterized by sadness, moodiness, and emotional instability.

5) Openness: This trait features characteristics such as imagination and insight, and those high in this trait also tend to have a broad range of interests.

\section{$\underline{\text { Sample }}$}

10 male participants were selected out of which 5 were Indian classical dancers and the other 5 were western dancers. Convenient sampling technique was used. The 5 classical dancers chosen had a training in Indian classical dance for more than 6 years and as well are stage performers whereas the western dancers were also stage performers but had no particular qualification in western dance styles but they had been doing dance for more than 6 years .

\section{$\underline{\text { Tool Used }}$}

Neo Five Factor Inventory (NEO FFI) was used developed by Paul T. Costa and Robert R. McCrae are the developers of this test. The test was developed in the year 1990. The self-report consists of 60 statements for the measurement of the big 5 personality dimensions.

\section{Procedure}

The permission was taken from the institute authorities and consent of the participants was taken to conduct the research. The participants were chosen according to their own will. The participants were given the instructions on how to fill the questionnaire, help was provided if any query was raised regarding the questions during the conduction of the test. After collecting the test sheets it was checked whether it was filled completely or not. Data analysis was done and interpretation was made according to the results obtained.

\section{Results and Discussion}

Result Table 1

\begin{tabular}{|c|c|c|c|c|c|}
\hline \multirow{2}{*}{ Big 5 Personality Factors } & \multicolumn{2}{|c|}{ Mean Value } & \multicolumn{2}{c|}{ SD } & $\mathrm{t}$ value \\
\cline { 2 - 6 } & Western Dancers & Classical Dancers & Western Dancers & Classical Dancers & \\
\hline Neuroticism & 20.2 & 21.8 & 7.54 & 2.63 & 0.39 \\
\hline Extraversion & 27.2 & 29.2 & 8.70 & 1.39 & 0.46 \\
\hline Openness & 28.6 & 24.8 & 4.45 & 1.83 & $1.86^{*}$ \\
\hline Agreeableness & 25.4 & 27.4 & 3.82 & 4.8 & 1.37 \\
\hline Conscientiousness & 31 & 34.4 & 4.60 & 1.49 & 1.54 \\
\hline
\end{tabular}

*0.05 level of significance

Result Table 2

\begin{tabular}{|c|c|c|c|c|c|c|}
\hline \multirow{2}{*}{ iig 5 Personality Factors } & \multicolumn{2}{|c|}{ Mean Value } & \multicolumn{2}{c|}{ T score } & \multicolumn{2}{c|}{ Qualitative description } \\
\cline { 2 - 6 } & Western Dancers & Classical Dancers & Western Dancers & Classical Dancers & Western Dancers & Classical Dancers \\
\hline Neuroticism & 20.2 & 21.8 & 57 & 57 & High & High \\
\hline Extraversion & 27.2 & 29.2 & 43 & 55 & Low & High \\
\hline Openness & 28.6 & 24.8 & 52 & 46 & Average & Average \\
\hline Agreeableness & 25.4 & 27.4 & 32 & 50 & Low low & Low \\
\hline Conscientiousness & 31 & 34.4 & 41 & Average \\
\hline
\end{tabular}

According to result table 1 , in openness dimension there is a significant difference found between the two groups ( $t$ value $1.86=1.86$ )indicating that there is a $95 \%$ chance that the same result will occur if the test is again carried out, where the mean of Indian classical dancers was more (28.6) than the mean of western dancers (24.8) . Whereas on the other four variables i.e., neuroticism, extraversion, agreeableness and conscientiousness there was no significant difference found.

According to result table 2, a qualitative analysis was done according to NEO-FFI manual. In neuroticism scores obtained by the two groups were similar and both group of dancers were high in this dimension. In extraversion there was major difference in the scores of the participants and
Indian classical dancers were high whereas western dancers were low in the dimension of extraversion. In openness scores obtained by the two groups did not differed much and both group of dancers were average in the dimension of openness. In agreeableness scores obtained by the two groups differed and western dancers were very low whereas Indian classical dancers were low in the dimension of agreeableness. In conscientiousness scores obtained by the two groups differed and western dancers were low whereas Indian classical dancers were average in the dimension of conscientiousness.

The hypothesis that there will be no significant difference between the personality of male Indian classical dancers and male western dancers was not retained. A significant

\section{Volume 6 Issue 12, December 2017}




\section{International Journal of Science and Research (IJSR) \\ ISSN (Online): 2319-7064}

Index Copernicus Value (2016): 79.57 | Impact Factor (2015): 6.391

difference was found in the dimension of openness. On the dimension of Openness Indian classical dancers have scored more than western dancers, this may be because openness consists of active imagination, aesthetic sensitivity, attentiveness to inner feelings,etc., and all these traits are comparatively more dominant in Indian classical dancers than western dancers. As focus on beautiful colourful costumes, makeup, etc., and various ways of representing single act and to be aware and quickly change expression with the change of the character is dominantly required in Indian classical dance.

\section{Limitations}

1) The sample size was fairly modest.

2) Since non-probability sampling method was used therefore it is difficult to generalize the result.

3) Use of an experimental design would have given more authenticity to the research.

4) Use of a more elaborate personality questionnaire would have increased the insight.

5) Narrowing down the dance styles within the two dance groups would have given a clearer out look.

\section{Conclusion}

Dance is through the movement of body's different parts and expressing your emotions through it. The present research was conducted to see the personality differences between male Indian classical dancers and male western dancers. The Indian classical dance forms are those forms of dancing in which each movement from head to toe is bound by rules. Western dance is characterised by great diversity and rapid change, many of its forms came into existence to show a sense of revolt and aggression. NEO-FFI was administered on the participants and its scoring and interpretation was made. The hypothesis was not retained and a significant difference in the dimensions of openness in personality was found between the male Indian classical dancers and male western dancers.

\section{References}

[1] Carlson,E., Burger, B., London,J., Thompson,M.R., \& Toiviainen,P.(2016) Conscientiousness and Extraversion relate to responsiveness to tempo in dance. National Institute of Health, 49, 315-25.

[2] Costa, P. T., Terracciano, A., \& McCrae, R. R. (2001).Gender differences in personality traits across cultures: robust and surprising findings. National Institutes of Health, 81(2) 322-31

[3] Cultural India.(n.d.). Retrieved from http://www.culturalindia.net/indian-dance/dancers/

[4] Cultural India.(n.d.). Retrieved from http://www.culturalindia.net/indian-dance/classical/

[5] Dance moves can reveal your personality. (n.d.). Retrieved

fromhttp://www.telegraph.co.uk/news/science/sciencenews/8131236/Dance-moves-can-reveal-yourpersonality.html

[6] Dance moves can reveal your personality.(n.d.). Retrieved http://www.telegraph.co.uk/news/science/sciencenews/8131236/Dance-moves-can-reveal-yourpersonality.html

[7] Feist,G.J.(1998). A meta analysis of personality in Scientific and artistic creativity. Personality and Social Psychology review, 2(4) 290-309.

[8] Indian classical dance.(n.d.). Retrieved from https://en.wikipedia.org/wiki/Indian_classical_dance

[9] Personality and dance.(n.d.). Retrieved from https://www.researchgate.net/publication/223667793_P ersonality_differences_between_young_dancers_and_n on-dancers

[10] Rawlings.D.,(2016). Psychology of music.Sage Journals. 25(2) 120-132

[11] Srivastava.K., (2012). Concept of personality: Indian perspective. Industrial Psychiatric Journal, 21(2), 8993

[12] The big 5 personality traits.(n.d.). Retrieved from https://www.verywell.com/the-big-five-personalitydimensions-2795422

[13] Western dance forms.(n.d.). Retrieved from http://mocomi.com/western-dance-forms/

[14] Western dance.(n.d.). Retrieved from https://www.britannica.com/art/Western-dance

[15] What your dance moves say about your personality. (n.d.). $\quad$ Retrieved from http://newsfeed.time.com/2010/11/15/what-your-dancemoves-say-about-your-personality/

[16] Yanna,J.W., Colin,G.D., \&Jacob,B.H.(2011) Gender Differences in Personality across the Ten Aspects of the Big Five. Frontiers in Psychology, 2, 178. 